\title{
Remote Oceanographic Instrumentation Integrated in a GRID Environment
}

\author{
S. Salon ${ }^{1}$, P.-M. Poulain ${ }^{1}$, E. Mauri ${ }^{1}$, R. Gerin ${ }^{1}$, D. Adami ${ }^{2}$ and F. Davoli ${ }^{3}$ \\ ${ }^{1}$ Istituto Nazionale di Oceanografia e di Geofisica Sperimentale OGS \\ B.go Grotta Gigante 42/c, 34010 Sgonico, Italy \\ e-mail: \{ssalon/ppoulain/emauri/rgerin\}@inogs.it \\ ${ }^{2}$ DII-University of Pisa / CNIT-University of Pisa Research Unit \\ Via G. Caruso 16, 56122 Pisa, Italy \\ e-mail:d.adami@iet.unipi.it \\ ${ }^{3}$ DIST-University of Genoa / CNIT-University of Genoa Research Unit \\ Via Opera Pia 13, 16145 Genova, Italy
}

e-mail:franco@dist.unige.it

(Received: 26 November 2008; published online: 25 March 2009)

\begin{abstract}
The observations provided by oceanographic remote instruments are essential to the purposes of the operational oceanography that represents a constantly growing tool to monitor and predict the state of the marine resources. The management of a network of instruments deployed in the Mediterranean Sea is a complex task that may be greatly supported by the GRID technology. This paper presents the activity planned by the DORII EU-FP7 project concerning the floats and the glider. The aim of the project is to demonstrate the potentiality of the state-of-the-art eInfrastructure in the integration of the data driven control/interaction workflow that characterizes the instruments. We describe the communication between the elements of the workflow and the associated network topology.
\end{abstract}

Key words: remote instrumentation, GRID technology, operational oceanography

\section{INTRODUCTION}

In the worldwide scientific effort oriented into the study of ocean environments, the monitoring, analysis and prediction of the behavior of the Mediterranean Sea is one of the main issue in which OGS is presently involved through EUsupported research projects. This issue is important in order to develop optimal management of the resources of the Mediterranean environment, avoiding irreversible and negative alterations, with a particular focus to the ecosystem. Each element of the ecosystem (i.e. water and living resources) is not studied stand-alone, but dealt with the fundamental interactions with the other components. Ideally, all the delicate and complex relationships between organisms (of all sizes) and physical processes (such as currents, sea temperature field, irradiance and atmospheric forcing fields) have to be taken into account.

To follow this goal, the development of instruments and techniques able to investigate the impact of anthropic and climate changes occurring nowadays represents a primary necessity. One of the fundamental stages of this study is the observation and measure of the physical state of the marine environment.

Operational oceanography constitutes a powerful tool to monitor, analyze and predict the state of the marine resources as well as the sustainable development of coastal areas [1]. Near real time (NRT) observations at the sea surface and in the water column, e.g., temperature and salinity $(\mathrm{T} / \mathrm{S})$ profiles, are of central importance for the operational forecasting system in the Mediterranean. The Mediterranean Sea has in fact a particularly strong salinity contribution to density and any observing system in support of nowcasting/forecasting should consider the combined observation of temperature and salinity profiles.

The management of an increasing number of observational instruments that includes the communication system, the data downloading and treatment, the post-processing and the visualization of the information gathered by the observations has recently grown in complexity. ICT infrastructures may greatly help in providing a remote control of the entire flow of information associated to the 
observational instruments, from the raw data measured by the sensor at sea (i.e. temperature, salinity, current velocity) to the data-processing software running on the researcher's laptop.

In particular, interactive applications of the GRID technology could support the management of the complex work flow related to the instrument interconnections (i.e. buoys, floats, autonomous vehicles), to the eventual technical problems bound to appear intermittently and the subsequent NRT corrections and/or adjustments of the sensors. Moreover, the communication to operative structures such as the Civil Protection or local/regional administrations represents a composite multi-task process that involves different actors and that could be successfully integrated in a GRID environment.

The following sections will give some details about the instruments that constitute two of the pilot applications considered by the DORII EU-FP7 project [2]. Then, a discussion about the strategy of implementation of the sensors in a workflow within the DORII project will be presented together with a general scheme of the network infrastructure.

\section{ARGO FLOATS IN THE MEDITERRANEAN SEA}

In the framework of the international Argo project, autonomous profiling floats are being deployed throughout the World's oceans and marginal seas, to monitor the spatial variability and temporal evolution of the water mass characteristics (temperature and salinity profiles down to 1000 or 2000 dbar).

Most of the Argo floats operated in the Mediterranean Sea are programmed in the "Park and Profile" configuration with a neutral parking depth of $350 \mathrm{~m}$ (near the salinity maximum of the Levantine Intermediate Water - LIW) and a maximum profiling depth of $700 \mathrm{~m}$, with a cycling period of 5 days. Every ten cycles, the floats are programmed to profile between $2000 \mathrm{~m}$ and the surface in order to sample deep water mass properties. When at surface, the floats are located by, and transmitted data, to the Argos system onboard the NOAA satellites. The sampling intervals for the vertical profiles are $5 \mathrm{~m}$ (above $100 \mathrm{~m}$ ), $10 \mathrm{~m}$ (between 100 and $700 \mathrm{~m}$ ) and $50 \mathrm{~m}$ (below $700 \mathrm{~m}$ ). The above mentioned technical and sampling characteristics were tailored to the specific Mediterranean hydrological and morphological conditions. The floats are deployed from both research vessels and from ships of opportunity. In particular, some floats are released from container and gas tanker ships cruising along Volunteer Observing Ship (VOS) XBT lines with typical speeds of 15-20 knots.

The float data are processed and archived in near-real time at the Archiving and Dissemination CORIOLIS Data Center (Brest, France) and are distributed on the GTS following the standards of the international Argo program. Mediterranean Argo full datasets can be visualized and downloaded in quasi-real time through the CORIOLIS Center [3]. Float trajectory plots and status tables are also produced in near-real time at the MedArgo Regional Argo Center at OGS [4], information can also be found in [5].

Along with XBT and satellite data, the NRT temperature and salinity data provided by the MedArgo profilers are the backbone of the data assimilation and forecast system at basin scale developed in the Mediterranean Forecasting System (MFS). Additionally, intermediate depth $(350 \mathrm{~m})$ mean currents are estimated near the LIW main core from the profiler displacements at their neutral depth.

In total, more than 90 floats have been deployed throughout the Mediterranean Sea since 2000, providing more than 7000 temperature and salinity profiles. In fall 2008, about 20 units were still working and the float population in the Mediterranean should increase to about 30 floats operating simultaneously in 2009.

\section{GLIDERS IN THE MEDITERRANEAN SEA}

Gliders are underwater autonomous vehicles which move up and down in the ocean by changing buoyancy. Wings allow steerable gliding, thus horizontal propulsion. Gliders trace a sawtooth profile, measuring temperature, conductivity (to calculate salinity), currents, chlorophyll fluorescence, optical backscatter, etc. versus depth. They navigate with the help of periodic surface GPS fixes, pressure sensors, tilt sensors, and magnetic compasses. Vehicle pitch is controllable by movable internal ballast (usually battery packs), and steering is accomplished either with a rudder (as in Slocum, see later). Buoyancy is adjusted by using a piston to flood/evacuate a compartment with seawater (Slocum). Commands and data are relayed between gliders and shore via the Iridium satellite telephone system.

Since 2007, OGS operates a Slocum electric glider to monitor the near-surface water column (down to $200 \mathrm{~m}$ ) in specific areas of the Mediterranean. Typically missions have been rather short (days to weeks) but it is planned to use the glider for longer missions (up to a month with alkaline batteries). More specifically, the OGS glider has 
been used in Maritime Rapid Environmental Assessment (MREA) experiments focused on the Ligurian Sea in collaboration with Italian and international research institutes, the Italian Navy and the NATO Undersea Research Centre [7].

\section{THE OCEANOGRAPHIC AND COASTAL OBSERVATION SENSOR NETWORK IN THE DORII PROJECT}

The main objective of the DORII project is the deployment of an eInfrastructure for those scientific communities where ICT technology is perceived as a big opportunity to boost their research but that, at present, results not fully exploited.

The instruments described in the previous sections have been selected as significant, easily expandable and portable/scalable test cases to show the potentiality of the GRID infrastructure in the integration of a data driven control/interaction flow. In particular, our goals are:

1. to demonstrate the feasibility of tracking the data flow from autonomous multi-parametric measuring platforms equipped with a variety of sensors;

2. to implement a GUI that could facilitate the operator control of the system functioning (this is particularly important for the glider, since its cost is much higher than that of the floats);

3 . to create a protocol for remote bi-directional control of the glider (and, in future, of the floats);

4. to provide an efficient data storage integrated in the GRID and a secure online data access to the researchers interested in using the data;

5. to make aware a larger oceanographic community of the potentialities rising from the integration of remote instrumentation in a GRID infrastructure.

We present here the plan we intend to follow in order to build the infrastructure to integrate the sensors in the GRID. Figure 1 shows the workflow as designed within the DORII project, numbers are related to the different communications between elements of the workflow:

1. The remote sensor sends/receives signals to/from satellites. Note that most floats can only send information to satellite, whereas glider can also receive it from the satellite and be programmed as to follow a specific route. The transmitter coupled to the sensor is programmed to send signals to satellites at periodic intervals. The communication arrow is unidirectional for the former and bidirectional for the latter.
2. Satellites (Argos or Iridium) pick up the signals, collect the data, store the data on-board and relay them in real-time back to the Earth (Ground Station).

3. By means of the Instrument Element, the sensor network is "virtualized" and data collected through the "sensor network" may be delivered to the developer/maintainer. The glider route may also be programmed and modified by the developer/maintainer. This is particularly important in case of malfunctioning of the glider in order to rescue it.

4. The developer/maintainer may access the system by using a VCR (Virtual Control Room).

5. Acquired data are stored by the Storage Element.

6. The pre-processing (e.g. quality check) and postprocessing applications are executed on the stored data by the Computing Element. Processing centres, such as OGS, collect all incoming data, process them and distribute them to the users.

7. Processed data are stored to the Storage Element.

8. The results can be visualized by the end users by means of the VCR.

9. Users around the world may access the data through a Web Server.

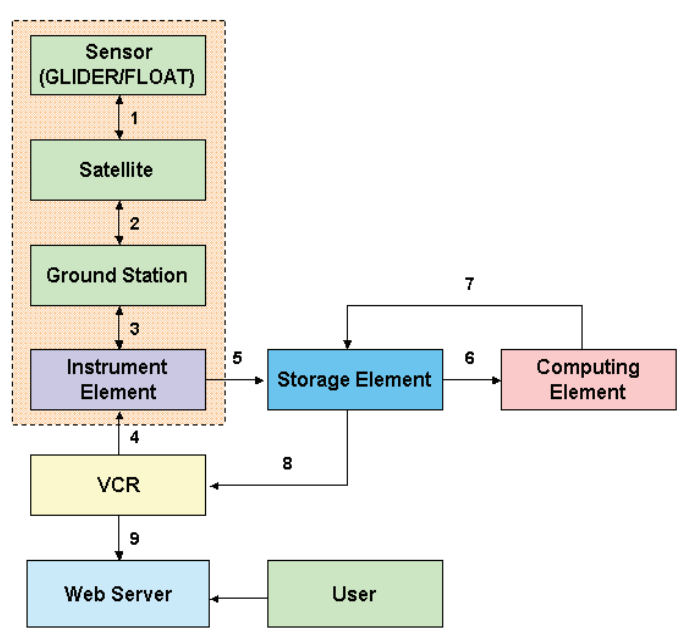

Fig. 1. Workflow designed for the OGS remote sensors. Note that bi-directional arrows 1, 2, 3 are related to glider that can be programmed by the Instrument element. In general, floats can only send information to Instrument Element via the satellite and the ground station

Following the deployment of the test case, we plan to disseminate the experience gained among the bigger scientific 
community involved in the Mediterranean Operational Oceanography Network (MOON, [8]). MOON acts as the Regional Operational Oceanography System (ROOS) recognized by the European organisation EuroGOOS [9], and is involved in the real-time delivery of operational products for the monitoring and forecast of the Mediterranean Sea conditions. This consortium is external to the DORII project, but we believe that the development software tools for the integration, the workflow control and simulations monitoring and steering in a GRID environment will be of paramount importance for the activities that MOON is conducting.

\section{NETWORK TOPOLOGY AND CONNECTIVITY}

The DORII network infrastructure allows OGS users to access different types of grid resources (Computing Elements, Storage Elements, Instrument Elements). Basically (see Fig. 2), the network infrastructure is organized according to three different hierarchical layers, corresponding to the access network, the distribution network and the core network, respectively. More specifically:

1. the access network is the Gigabit Ethernet LAN located at OGS site. The goal of the LAN is to connect local computational and storage resources and sensor networks (FLOAT, GLIDER), virtualized by means of Instrument Elements, to the
DORII network, so as to be also shared among different Virtual Organizations (VOs);

2. the distribution network, corresponding to GARR, the Italian National Research network, connects the local network to the core one;

3. the core network is based on GÉANT [10] and represents the infrastructure necessary to interconnect the local network to other DORII computational and storage resources.

As far as QoS requirements are concerned, FLOAT and GLIDER may be classified as applications working on precollected data, and therefore they do not have stringent constraints in terms of end-to-end delay and jitter. The amount of data exchanged in each session by both applications is small (in the order of hundreds of MB), whereas network reliability is required, since packet loss cannot be tolerated.

Bandwidth reservation is not necessary, but a Better than Best-Effort network service may help improving the performance of the applications.

It is worth highlighting that a new enhanced version of GLIDER, which enables real-time operational control of the sensor from a remote site, is currently being designed and will be developed in the near future. In this case, low delay and jitter must be guaranteed to allow real-time interactivity. On-demand guaranteed bandwidth connection seems to be the most suitable network service to be deployed.

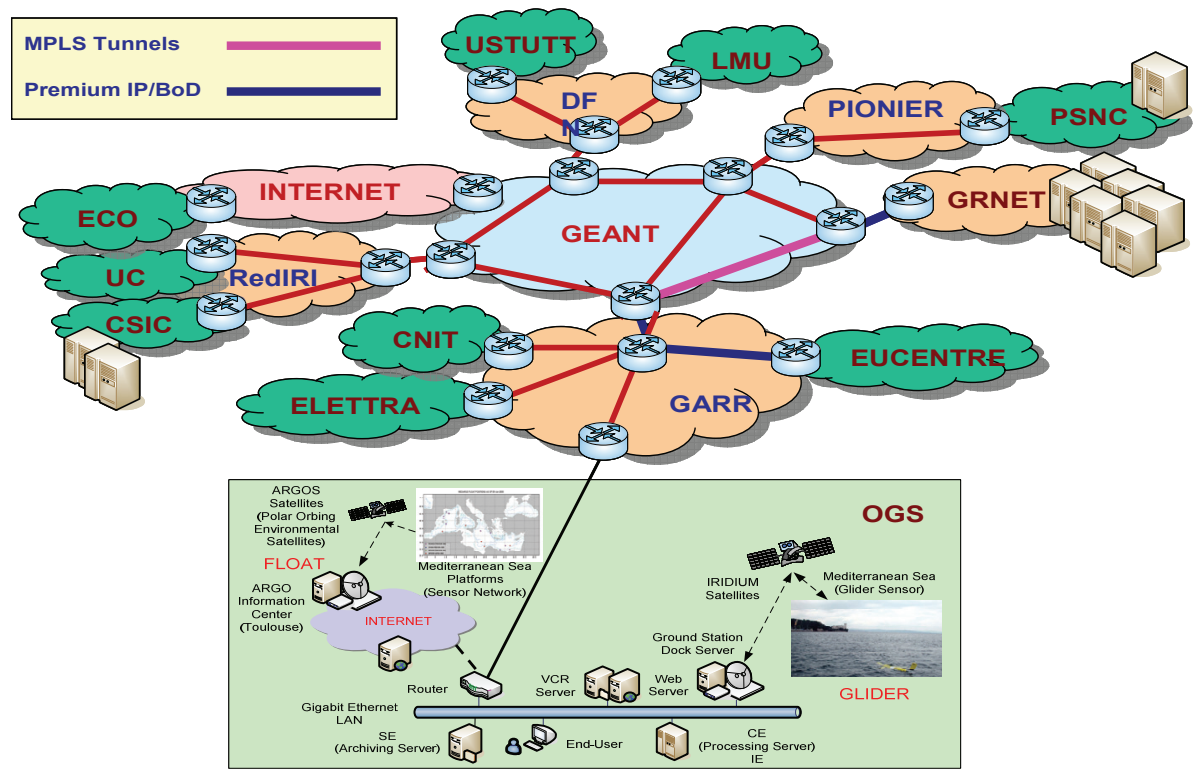

Fig. 2. Scheme of the DORII network infrastructure. 
The core network infrastructure will be based on GÉANT, the pan-European research and education network covering more than 30 countries. A meshed topology based on Multiprotocol Label Switching (MPLS, [11]) tunnels might be the most suitable solution for the DORII core network, since in this way survivability is assured in case of failures.

The meshed topology should map the logical topology of the VOs corresponding to the computational elements, storage elements and instrument elements used for the oceanographic applications.

\section{CONCLUDING REMARKS}

The main objective of the DORII project is the deployment of an eInfrastructure for those scientific communities where ICT technology is perceived as a big opportunity to boost their research but that, at present, results not fully exploited.

As explained in the MERSEA website [12], "operational oceanography is a growing global business". This means that Europe may become a leader in this business following a systematic integration of resources and a strong collaboration that involves European institutes and companies. The development of global/regional monitoring and forecasting systems and the future availability of the products of these systems will drive more and more requirements by an even larger community: the spectrum of operational prediction products will hence increase to further include industrial, governmental and other potential users and clients. Access to the products provided by the operational oceanography resources (such as data collected by floats and gliders) coupled with the assistance of the GRID technology will be helpful to establish services able to improve security, safety and cost effectiveness of offshore activities.

NRT observations are therefore fundamental products of the operational oceanography projects where OGS is presently involved. The access, management and control of distributed remote instrumentation like vertical profilers of the water column, even passive (floats) and active (gliders), represent a challenge for the GRID technology.

The final products (data) will be distributed to the WWW and offered, in addition to the research community, to policy makers of maritime administrations, planners of offshore operations such as oil exploration/extraction and ship routing, environment and fishery managements, tourism providers and whoever will have benefits from knowing NRT sea-state observations. The fast communication to operative/rescue structures such as the Civil Protection, Coast Guards and local/regional administrations thus represents a composite multi-task process that involves different actors and that could be supported by the GRID technology.

\section{References}

[1] N. C. Flemming, S. Vallerga, N. Pinardi, H. W. A. Behrens, G. Manzella, D. Prandle and J. H. Stel (eds), Operational Oceanography - Implementation at the European and Regional Scales. Elsevier Oceanography Vol. 66. Elsevier, Amsterdam (2002).

[2] See the official web page of the DORII project, $\mathrm{http} / / / w w w . d o r i i . e u / h o m e$

[3] See the official web page of the CORIOLIS Centre, http://www.coriolis.eu.org/

[4] See the official web page of the MedARGO project hosted at OGS - http://poseidon.ogs.trieste.it/sire/medargo.

[5] P.-M. Poulain, R. Barbanti, J. Font, A. Cruzado, C. Millot, I. Gertman, A. Griffa, A. Molcard, V. Rupolo, S. Le Bras and L. Petit de la Villeon, MedArgo: a drifting profiler program in the Mediterranean Sea. Ocean Science 3, 379395 (2007).

[6] See the official web page of the Mediterranean Forecasting System - http://gnoo.bo.ingv.it/mfs/

[7] R. Gerin, E. Mauri and P.-M. Poulain, Prime missioni dello Slocum Electric Glider: TS-TEST (Trieste, 7-8 giugno 2007) e MREA07 (La Spezia, 19-21 giugno 2007), REL. OGS 2007/73 OGA 19 SIRE, Trieste, Italy, 31 pp (2007). http://doga.ogs.trieste.it/sire/glider/mrea07-lasie07.html

[8] See the official web page of the Mediterranean Operational Oceanography Network, $\mathrm{http} / / /$ www.moon-oceanforecasting.eu/

[9] See the official web page of EuroGOOS, http://www.eurogoos.org/

[10] See the official web page of GÉANT, http://www.geant.net/

[11] E. Rosen, A. Viswanathan and R. Callon, Multiprotocol Label Switching. IETF RFC 3031 (2001). http://www.ietf.org/rfc/rfc3031.txt

[12] See the official web page of the MERSEA project, http://www.mersea.eu.org/. 

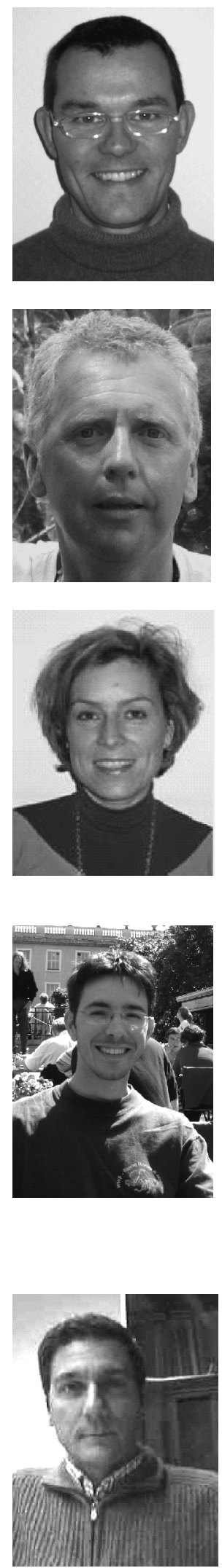

Stefano Salon graduated in Physics (1998) and got a PhD in Applied Geophysics and Hydraulics (2004) at the University of Trieste. Post-Doc at OGS from 2004 to 2007, he has been a researcher at OGS since December 2007. His research interests focus on turbulence in tidally-driven boundary layers, operational numerical forecasts of the Mediterranean ecosystem, dynamical downscaling of the ecosystem of the lagoon of Venice based on IPCC-SRES scenarios. He is a component of the Academic Board of the School of Doctorate in Environmental and Industrial Fluid Mechanics (Univ. of Trieste) where in 2008 he taught a course in Geophysical Fluid Dynamics.

Pierre-Marie Poulain holds a Ph.D. degree in Oceanography from the University of California San Diego (1989). He has worked at the University of Miami (Miami, Florida), the NATO Undersea Research Centre (La Spezia, Italy) and the Naval Postgraduate School (Monterey, California) on the surface circulation in the Pacific Ocean and Mediterranean Sea as inferred from Lagrangian drifter data. Since 2000 he has been a senior scientist at OGS. As head of the Remote Sensing Group, he is coordinating research activities based on data collected by autonomous instruments (drifters, floats, gliders, HF coastal radars) and satellite sensors. Dr. Poulain has more than 50 peer-reviewed publications in oceanography.

Elena MAURI holds a B.S. in Biological Science (Laurea) from the University of Trieste (1992) and a M.S. in Marine Science from Moss Landing Marine Laboratories (San Jose State University,CA, USA 2000). She worked at MBARI (Monterey Bay Aquariun Reasearch Institute, Moss Landing, CA.USA) on bio-optical data, algorithm and semi analytical models testing. Since October 2000 she has been at OGS, involved mainly in satellite oceanography and bio-optics research. She is also involved in the acquisition of real time data using autonomous systems such as floats and gliders.

RiCCARdo Gerin graduated in Physics (2001) and got a PhD in Marine Environmental Science (2005) at the University of Trieste. He has been a Post-Doc researcher at OGS since May 2005. His research activity (at sea and in the lab) is mainly oriented on the study of the near surface circulation of the Mediterranean Sea. Since 2007 he has also been operating the OGS Glider (deployment/recovery, piloting, ballasting and testing).

DAVIDE ADAMI received a degree in Electronic Engineering from the Department of Information Engineering at the University of Pisa, Italy, in 1992. From 1993 to August 1997 he worked at Consorzio Pisa Ricerche in the field of computer and Telecommunications networks, with particular focus on dial-up internetworking of TCP/IP networks, taking part in a large number of research projects funded by the Regione Toscana and the European Community. Within the project Internet, he was the Network Administrator of Towernet, one of the earliest ISP in Italy, where he was concerned with policy routing and intradomain routing protocols (RIP, OSPF). In the framework of the MAESTRO ACTS project he has been dealing with Quality of Service Networks in ATM networks and Resource Allocation Techniques (RSVP). In September1997 he joined to the CNIT (National Consortium for Telecommunications), where he is a senior researcher in the field of telecommunications networks. His research interests mainly concern the provisioning of Quality of Service in IP networks and the TCP/IP enhancements for satellite networks. He is one of technical responsible of the CNIT satellite network. Currently, he is also an Assistant Professor at the Faculty of Engineering of the University of Pisa in the courses of "Planning and Simulation of Telecommunications Networks" and "Systems and Services of Telecommunications Networks". 
Franco Davoli received a degree in Electronic Engineering in 1975 from the University of Genoa, Italy. Since 1990 he has been Full Professor of Telecommunication Networks at the University of Genoa, at the Department of Communications, Computer and Systems Science (DIST). His current research interests are in dynamic resource allocation in multiservice networks, wireless mobile and satellite networks, and multimedia communications and services. He has co-authored over 250 scientific publications in international journals, book chapters and conference proceedings. He is a member of the Editorial Board of the International Journal of Communication Systems (Wiley) and of the international journal Studies in Informatics and Control, and an Area Editor of Simulation - Transactions of the SCS. In 2004, he has been the recipient of an Erskine Fellowship from the University of Canterbury, Christchurch, New Zealand, as Visiting Professor. He has been Principal Investigator in a large number of projects and has served in several positions in the Italian National Consortium for Telecommunications (CNIT). He was the Head of the CNIT National Laboratory for Multimedia Communications in Naples for the term 2003-2004, and Vice-President of the CNIT Management Board for the term 2005-2007. He is a Senior Member of the IEEE. 